The Geological Society of America

Special Paper 504

2014

\title{
How low can you go? Maximum constraints on hydrogen concentrations prior to the Great Oxidation Event
}

\author{
Shawn Domagal-Goldman* \\ Research Space Scientist, Planetary Environments Laboratory, National Aeronautics and \\ Space Administration Goddard Space Flight Center, 8800 Greenbelt Road, Greenbelt, Maryland 20771, USA
}

\begin{abstract}
Shaw postulates that Earth's early atmosphere was rich in reducing gases such as hydrogen, brought to Earth via impact events. This commentary seeks to place constraints on this idea through a very brief review of existing geological and geochemical upper limits on the reducing power of Earth's atmosphere prior to the rise of oxygen. While these constraints place tight limits on this idea for rocks younger than $3.8 \mathrm{Ga}$, few constraints exist prior to that time, due to a paucity of rocks of that age. The time prior to these constraints is also a time frame for which the proposal is most plausible, and for which it carries the greatest potential to explain other mysteries. Given this potential, several tests are suggested for the $\mathrm{H}_{2}$-rich early Earth hypothesis.
\end{abstract}

\section{INTRODUCTION}

Shaw (this volume) contends the pre-oxygen Earth was more reducing than previously thought. That suggestion can be considered in the context of past research on the redox state of the atmosphere using geochemical measurements and atmospheric models. The call for an $\mathrm{H}_{2}$-rich atmosphere is intriguing because it contains some explanatory power; however, we can limit this idea in scope, given knowledge obtained through past analyses of the Earth's geological record. The "sweet spot" for this hypothesis is for the earliest portion of the planet's history. This is a time when the rock record cannot exclude this as a possibility, when the impact-driven mechanism for this phenomenon was most prevalent, and when this idea has the greatest potential to solve perplexing riddles.

This idea is intriguing because it probes the opposite end of the oxidizing-reducing scale on which much of the past debate and research have been focused. Past research, as evidenced by a later paper in this series by Ohmoto et al. (this volume), has debated the limits on the oxidizing extent of early Earth. However, significantly less consideration has been given to limitations on the reducing potential of early Earth's atmosphere. This is where Shaw's hypothesis comes into play.

\section{DISCUSSION}

To evaluate the possibility of a highly reducing atmosphere on early Earth, we consider geological constraints that place an upper limit on the reducing power of the atmosphere. These include data used to argue for a "whiff" of oxygen in the midArchean (e.g., Anbar et al., 2007). These conclusions—based on the concentrations of elements for which mobility is sensitive to the redox state of the atmosphere-ocean system-place periodic, yet strict, limits on how reducing the atmosphere could have been

\footnotetext{
*shawn.goldman@nasa.gov

Domagal-Goldman, S., 2014, How low can you go? Maximum constraints on hydrogen concentrations prior to the Great Oxidation Event, in Shaw, G.H., ed., Earth's Early Atmosphere and Surface Environment: Geological Society of America Special Paper 504, p. 11-13, doi:10.1130/2014.2504(02). For permission to copy, contact editing@geosociety.org. (C) 2014 The Geological Society of America. All rights reserved.
} 
between ca. 2.8 and ca. $2.5 \mathrm{Ga}$. Unless some mechanism could have rapidly oxidized the atmosphere, and then rapidly returned it to a highly reducing state, we must therefore rule out an $\mathrm{H}_{2}$-rich atmosphere for this time period.

Further constraints come from the presence of massindependent sulfur isotope fractionation (S-MIF). Highly reducing conditions can upset the exit channel balance between sulfates and sulfides, a balance that is needed to transfer atmospherically derived isotopic features to the rock record. Under extremely reducing conditions, all $\mathrm{S}$ in the atmosphere will leave in the form of sulfides, and this will eliminate any S-MIF created before it is deposited (Domagal-Goldman, et al., 2008). Extremely reducing conditions also would have caused the $\mathrm{CH}_{4} / \mathrm{CO}_{2}$ ratio in the atmosphere to approach unity. Had this occurred, a haze would have formed, blocking the ultraviolet (UV) wavelengths responsible for S-MIF production (Zerkle et al., 2012). Given the presence of S-MIF from 3.8 Ga through the rise of oxygen (Farquhar and Wing, 2003), we can eliminate the possibility of an $\mathrm{H}_{2}$-rich atmosphere for any time after $3.8 \mathrm{Ga}$.

The potential for haze formation places another constraint on $\mathrm{CH}_{4}$ concentrations for a climatic reason: Hazes cause significant antigreenhouse effects. These effects will be much greater than the greenhouse effects from $\mathrm{CH}_{4}$ and other organic gases (Pavlov et al., 2001). For $\mathrm{CH}_{4} / \mathrm{CO}_{2}$ ratios significantly above 0.1 , global glaciations would have been triggered. However, there is no evidence for global glaciations prior to $2.4 \mathrm{Ga}$, nor for any glaciations prior to ca. $2.8 \mathrm{Ga}$. This corroborates the limit stated above: $\mathrm{CH}_{4}$ concentrations must have been less than $\mathrm{CO}_{2}$ concentrations since at least $3.8 \mathrm{Ga}$. Such conditions are not consistent with an $\mathrm{H}_{2}$-rich atmosphere.

Prior to $3.8 \mathrm{Ga}$, there is not much of a rock record, so these geological constraints do not exist. However, there are minerals that have been dated to be as old as $4.4 \mathrm{Ga}$, and analyses of these suggest that the redox state of the mantle has been relatively consistent throughout Earth's history (Trail et al., 2011). In terms of Shaw's hypothesis for an $\mathrm{H}_{2}$-rich atmosphere, this means that had such an atmosphere been in place prior to $3.8 \mathrm{Ga}$, it did not have a significant effect on the redox state of the mantle. Thus, the (admittedly sparse) geological data prior to $3.8 \mathrm{Ga}$ cannot exclude the possibility of an $\mathrm{H}_{2}$-rich atmosphere-they can only limit the degree to which the mantle would have been affected by such an atmosphere.

The time period prior to $3.8 \mathrm{Ga}$ is also the time when Shaw's hypothesis is most appropriately applied. The mechanism proposed to drive the atmosphere to such a state is the delivery of highly reducing extraterrestrial materials. The rate of delivery of this material would have significantly decreased with time, with perhaps a spike in delivery rates associated with the still controversial "Late Heavy Bombardment" at 3.8 Ga. Regardless, prior to $3.8 \mathrm{Ga}$, significantly more of this reducing material would have been delivered to Earth. Further, if the pre-3.8 Ga Earth had been more reduced, it would have allowed for greater abiotic production of compounds necessary for the origins of life, and for the buildup of extremely efficient greenhouse gases that could solve the "faint young sun paradox" during the time frame for which the Sun was at its faintest.

If escape of $\mathrm{H}$ through the top of the atmosphere was limited by energy deposition to the atmosphere (as opposed to limited by diffusion of $\mathrm{H}$ into the upper atmosphere, as it is on modernday Earth), then escape of $\mathrm{H}$ would have been much slower. If this was case, then the "oxidant source" provided by escape of $\mathrm{H}$ would have been lower, and the atmosphere would have been much more reducing. Previous models of escape show that this could produce a dramatic effect (Tian et al., 2005). However, such models have been criticized for not being complete enough (Catling, 2006), and further study is warranted before this process can be considered a potential mechanism for maintaining a reducing atmosphere on early Earth.

Future research could test this " $\mathrm{H}_{2}$-rich early Earth" hypothesis. First, one must determine if models of the impacts themselves that delivered the reducing material would have allowed this material to be partitioned into the atmosphere and crust without significant effects on the redox state of the mantle. Then, it must be demonstrated that an atmosphere such as this would have been capable of evolving into the considerably more $\mathrm{H}_{2}$-poor atmosphere that was in place since at least $3.8 \mathrm{Ga}$. Finally, models that reproduce this evolution should also be able to predict the resulting changes to noble gas and isotopic reservoirs, ultimately leading to "ground-testing" of the hypothesis with geochemical measurements of rocks deposited after this evolution was complete. Alternatively, should we be fortunate enough to uncover (meta-)sedimentary rocks older than $3.8 \mathrm{Ga}$, or develop the capability to find them on the Moon, we will be able to analyze them for some of the same geochemical constraints, such as the presence of S-MIF, that limit $\mathrm{H}_{2}$ concentrations after this time.

\section{ACNOWLEDGMENTS}

This work was performed as part of the NASA Astrobiology Institute's Virtual Planetary Laboratory, supported by the National Aeronautics and Space Administration through the NASA Astrobiology Institute under solicitation No. NNH05ZDA001C; it was also supported by the Oak Ridge Associated Universities NASA Postdoctoral Program.

\section{REFERENCES CITED}

Anbar, A.D., Duan, Y., Lyons, T.W., Arnold, G.L., Kendall, B., Creaser, R.A., Kaufman, A.J., Gordon, G.W., Scott, C., Garvin, J., and Buick, R., 2007, A whiff of oxygen before the Great Oxidation Event?: Science, v. 317, no. 5846, p. 1903-1906, doi:10.1126/science. 1140325 .

Catling, D.C., 2006, Comment on "A hydrogen-rich early Earth atmosphere". Science, v. 311, no. 5757, p. 38, doi:10.1126/science.1117827.

Domagal-Goldman, S.D., Kasting, J.F., Johnston, D.T., and Farquhar, J., 2008, Organic haze, glaciations and multiple sulfur isotopes in the mid-Archean Era: Earth and Planetary Science Letters, v. 269, p. 29-40, doi:10.1016/j .eps1.2008.01.040.

Farquhar, J., and Wing, B.A., 2003, Multiple sulfur isotopes and the evolution of the atmosphere: Earth and Planetary Science Letters, v. 213, p. 1-13, doi:10.1016/S0012-821X(03)00296-6. 
Ohmoto, H., Watanabe, Y., Lasaga, A.C., Naraoka, H., Johnson, I., Brainard, J., and Chorney, A., 2014, this volume, Oxygen, iron, and sulfur geochemical cycles on early Earth: Paradigms and contradictions, in Shaw, G.H., ed., Earth's Early Atmosphere and Surface Environment: Geological Society of America Special Paper 504, doi:10.1130/2014.2504(09).

Pavlov, A.A., Brown, L.L., and Kasting, J.F., 2001, UV shielding of $\mathrm{NH}_{3}$ and $\mathrm{O}_{2}$ by organic hazes in the Archean atmosphere: Journal of Geophysical Research-Planets, v. 106, p. 23,267-23,287, doi:10.1029/2000JE001448.

Shaw, G.H., 2014, this volume, Evidence and arguments for methane and ammonia in Earth's earliest atmosphere and an organic compound-rich early ocean, in Shaw, G.H., ed., Earth's Early Atmosphere and Surface Environment: Geological Society of America Special Paper 504, doi:10.1130/2014.2504(01)
Tian, F., Toon, O.B., Pavlov, A.A., and De Sterck, H., 2005, A hydrogen-rich early Earth atmosphere: Science, v. 308, p. 1014-1017, doi:10.1126/ science. 1106983.

Trail, D., Watson, E.B., and Tailby, N.D., 2011, The oxidation state of Hadean magmas and implications for early Earth's atmosphere: Nature, v. 480, p. 79-82, doi:10.1038/nature 10655 .

Zerkle, A.L., Claire, M.W., Domagal-Goldman, S.D., Farquhar, J., and Poulton, S.W., 2012, A bistable organic-rich atmosphere on the Neoarchaean Earth: Nature Geoscience, v. 5, p. 359-363, doi:10.1038/ngeo1425.

Manuscript AcCePted by the Society 8 November 2013 
Downloaded from specialpapers.gsapubs.org on March 2, 2015 


\title{
Geological Society of America Special Papers
}

\section{How low can you go? Maximum constraints on hydrogen concentrations prior to the Great Oxidation Event}

\author{
Shawn Domagal-Goldman \\ Geological Society of America Special Papers 2014;504; 11-13 \\ doi:10.1130/2014.2504(02)
}
E-mail alerting services click www.gsapubs.org/cgi/alerts to receive free e-mail alerts when new articles cite this article
Subscribe click www.gsapubs.org/subscriptions to subscribe to Geological Society of America Special Papers
Permission request click www.geosociety.org/pubs/copyrt.htm\#gsa to contact GSA.

Copyright not claimed on content prepared wholly by U.S. government employees within scope of their employment. Individual scientists are hereby granted permission, without fees or further requests to GSA, to use a single figure, a single table, and/or a brief paragraph of text in subsequent works and to make unlimited copies of items in GSA's journals for noncommercial use in classrooms to further education and science. This file may not be posted to any Web site, but authors may post the abstracts only of their articles on their own or their organization's Web site providing the posting includes a reference to the article's full citation. GSA provides this and other forums for the presentation of diverse opinions and positions by scientists worldwide, regardless of their race, citizenship, gender, religion, or political viewpoint. Opinions presented in this publication do not reflect official positions of the Society.

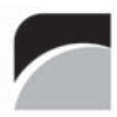

THE GEOLOGICAL SOCIETY OF AMERICA 